\title{
MENIN, Maria Suzana de Stefano; SHIMIZU, Alessandra de Morais (Orgs). Experiência e Representação Social: questões teóricas e metodológicas. São Paulo: Casa do Psicólogo, 2005. 319 p.
}

\author{
Ednea Rodrigues Albuquerque* \\ Márcia Alves Tenório Basílio*
}

\begin{abstract}
A Teoria das Representações Sociais (TRS) é discutida à luz de diversos olhares no livro intitulado Experiência e Representação Social: Questões Teóricas e Metodológicas, organizado pelas psicólogas Maria Suzane de Stefano Menin e Alessandra de Morais Shimizu e publicado pela editora Casa do Psicólogo. A obra está dividida em três partes. A primeira parte, "Discutindo relações entre experiência e representação social", apresenta uma discussão sobre o conceito de experiência, relacionando-o à Teoria das Representações Sociais. A segunda parte refere-se a "Questões metodológicas no estudo das representações sociais" e a terceira se debruça sobre "Experiências que constroem representações sociais". O referido livro congrega dez artigos elaborados por docentes-pesquisadores renomados em nível nacional e internacional.
\end{abstract}

O artigo "Experiência e representações sociais", de autoria de Denise Jodelet, é o único que integra a primeira parte da obra. Nele a autora discute a relação experiência e representações sociais, considerando que esse é um campo pouco explorado. Reitera que representações sociais são formas de conhecimento do senso comum, difundidas através da comunicação e das pertinências sociais e culturais. Nessa perspectiva, Jodelet procura relacionar as representações sociais e a noção de experiência enquanto fenômeno e conceito. Assim, discorrer sobre modos de vida e motivação pragmática implica pensar na observação, descrição, visibilidade, narrabilidade das ações, o que resulta numa realidade prática, naquilo que a autora coloca como "descritibilidade".

Segundo Jodelet, o campo da educação torna-se um espaço privilegiado para tal estudo. Entre os assuntos nele enfocados, podem ser destacados os seguintes: os diferentes níveis no sistema educativo; a definição das finalidades e modalidades da formação docente; o nível da hierarquia institucional; as práticas das políticas educacionais e os usuários do sistema escolar, ou seja, os pais e alunos. Considerando os estudos de Dubet (1994) sobre as representações do papel do professor, e as pesquisas de

\footnotetext{
“Doutoranda em Educação pela UFPE. E-mail: ednearo@oi.com.br "* Mestradanda em Educação pela UFPE. E-mail: marciaalvesbasilio@yahoo.com.br
}

Gillt (1980), a autora afirma que é possível constatar que as representações de alunos e professores são modificadas através do contexto histórico e que a função docente se estabelece a partir desse efeito na instituição escolar.

Outro exemplo entre a articulação do vivido e dos conhecimentos diz respeito às representações do corpo. A mudança cultural, ocorrida no fim dos anos sessenta, através dos movimentos de liberação sexual, da revolução feminista e da difusão do conhecimento, influenciou as modificações na relação com o corpo. Isto é, passamos de uma representação centrada no domínio biológico e ascendemos a uma representação mais aberta às dimensões da vida corporal, a uma entrada mais rápida pelo prazer e pelo hedonismo. Jodelet analisa, através dessa pesquisa, como homem e mulher retratam seus conhecimentos anátomo-fisiológicos e como estão dialeticamente representados e valorizados em relação ao vivido, conhecido e experienciado.

A díade representação social e experiência incrementa a passagem do plano coletivo para o singular e do plano social para o individual sem tirar do foco o lugar das representações sociais e suas formas de funcionamento, as quais, otimizadas pela comunicação social, suplementam a construção representacional.

Em suma, o artigo de Jodelet fomenta a utilidade de recorrer à análise da experiência, acreditando que ela pode assumir uma função reveladora na condução de novas representações. Com muita maestria, a autora sinaliza que estudiosos brasileiros estão instituindo um grupo de pesquisa sobre as representações, as significações emprestadas e a experiência vivida na prática de ritos religiosos afro-brasileiros. Conclui seu artigo revelando a intencionalidade das representações sociais como uma abordagem que contribui para a colocação de novos valores e reformulação da identidade social através de uma nova representação de si.

$\mathrm{Na}$ abertura da segunda parte da obra, o artigo "Pesquisa em representações sociais: a produção de 2003", de Angela Arruda, apresenta o resultado da pesquisa brasileira sobre representações sociais no ano de 2003, através de trabalhos publicados 
nos anais da III Jornada Internacional sobre Representações Sociais (JIRS). O referido artigo desenha o estado da arte dos 187 trabalhos que foram publicados na íntegra: Educação, Saúde, Comunicação e Ciência, Memória e Cultura; Política e Justiça, Problemas Brasileiros. Os números revelam que a Educação demonstra ser um campo de pesquisa em expansão, além da área de Saúde, com um bom quantitativo de trabalhos. A autora nos permite entender que os critérios elencados para a seleção dos trabalhos publicados seguiram a seguinte classificação: referencial teórico, dimensão da população estudada, procedimentos de coleta dos dados e de análise do material.

O trabalho consiste no cruzamento dos dados entre a preferência teórica e a definição de procedimentos de análise do material. O destaque para esse essa relação é a área da Saúde, que apresenta coerência entre os dois aspectos. Já a Educação revela a menor diferença e as demais áreas sinalizam uma fragilidade metodológica.

Os resultados apresentados por Arruda revelam que os dez temas mais frequentes na produção de 2003 estão assim focados: trabalho e práticas profissionais - $14,5 \%$; exclusão social e violência 12,1\%; processos ligados à saúde /doença: saúde reprodutiva e AIDS - 9,7\%; desenvolvimento humano $-8,9 \%$; processos educacionais e saúde mental - $8 \%$ cada um. $O$ interessante nos resultados é o envolvimento dos pesquisadores na discussão e no compromisso com a realidade do país.

Nos comentários e questões para reflexão, a referida autora explicita os limites da compreensão da TRS: a confusão entre representações com listas de categorias, percepções, imagens ou opiniões; a dificuldade de identificar as RS; o uso dos programas às vezes mascara as representações. Esclarece que se faz necessário explicar a representação na sua inserção sociocultural e na condição rizomática, através da gênese, ou do princípio organizador e do núcleo central. Além disso, Arruda apresenta conceitos próprios da teoria (os de ancoragem e núcleo central) e comenta sobre a banalização dos mesmos no corpo dos trabalhos. Ressalta ainda a obra de Moscovici, a qual adverte ao pesquisador que o trato com a interpretação e a fundamentação teórica qualificará a pesquisa, mesmo sem passar por um virtuosismo metodológico.

"Educação e representação social: tendências de pesquisa na área - Período de 2000 a 2003" é o destaque do terceiro artigo. As pesquisadoras e autoras Stefano \& Shimizu analisam as características dos trabalhos brasileiros mais recentes sobre representações sociais, aplicados ao campo da Educação. Elas tratam das questões conceituais sobre representações sociais, apoiando-se na abordagem de Jodelet, e afirmam seu interesse por dois campos: a relação conhecimento científico e popular e questões de ordem metodológica. Os seus achados constatam o quanto a Teoria das Representações Sociais é um referencial promissor para revelar os conhecimentos do senso comum, presentes na educação através dos seus diversos protagonistas. A teoria também tem contribuído para identificar relações entre representações sociais, ideologia e funções sociais, escolares e políticas na educação.

Os estudos conferiram apropriado destaque às representações presentes, mas revelam pouco sobre sua origem. São pouco exploradas as comparações entre conhecimentos escolares apresentados na forma da representação social e conhecimentos escolares de cunho mais científico. As pesquisas apontam que faltam estudos que promovam a análise de conteúdos e processos cognitivos das representações, estudos que explorem uma abordagem mais antropológica e sociológica, e sinalizam amostras com menos de 220 sujeitos. Evidenciam-se no estudo algumas pesquisas que investigaram transformações nas representações. São apresentadas mais pesquisas de cunho descritivo que explicativo. As autoras constataram, ainda, que as pesquisas em representações sociais estão inovando nos recursos para as análises de conteúdo com o uso dos softwares.

No quarto artigo, "Entrevista: anotações para pesquisadores iniciantes", Eugênia Coelho Paredes apresenta a entrevista como um recurso de pesquisa que vai além de um simples instrumento de coleta, já que pela mesma, através do discurso dos sujeitos, é possível adentrar nos códigos de percepção, na memória e na afetividade dos depoentes. Tomando o cuidado de exemplificar com algumas pesquisas, a autora aponta alguns cuidados metodológicos que não podem ser dispensados no uso da entrevista: para organizá-la, é necessário saber problematizar o objeto e saber o que se quer conhecer acerca do objeto a partir do problema elaborado; para coletar uma produção verbal pertinente, adequada, os pesquisadores precisam, também, dedicar muita atenção à organização do conjunto dos informantes. Outro aspecto relevante diz respeito às variáveis que determinam os contatos a serem realizados: idade, sexo, nível instrucional, entre outras.

A autora afirma que o domínio da entrevista só ocorrerá com a experiência, e para o iniciante um bom roteiro de entrevista poderá auxiliar nesse empreendimento. Após obter as informações sobre o objeto que se quer estudar, ou seja, após a coleta de dados, é importante a organização desses elementos em categorias que podem surgir a partir dos dados coletados, como é feito na análise de conteúdo, ou que podem ser pré-estabelecidas; discutir o texto digitado com os informantes, para a autora, é uma questão de ética, mas também saber ajudar o interlocutor a sintetizar suas ideias e auxiliar aquele que 
não consegue se expressar faz parte do ofício do entrevistador; o silêncio também é um discurso a ser apreendido; o processamento e a análise dos dados de uma entrevista pressupõem bastante atenção do pesquisador; tanto se for feita por um software quanto se for realizada por uma análise de discurso, a entrevista exigirá do pesquisador muito cuidado em distinguir os elementos e esquadrinhar os significados, já que será ele quem interpretará os dados.

À guisa das representações sociais, a autora, baseando-se em Jodelet, traz as perguntas que devem servir de guia para quem utiliza a teoria: o que, quem, como, de onde se sabe e com que efeitos? Ressalta, porém, que não é uma receita pronta, mas um caminho pelo qual se deve refletir.

O quinto artigo, intitulado "Análise estatística de dados textuais na pesquisa das representações sociais: alguns princípios e uma aplicação ao campo de saúde", de Denise Oliveira, Antonio Gomes e Sergio Marques, tem por finalidade explicar a metodologia da Análise Estatística Textual de Dados e seus desdobramentos. Como exemplo desse tipo de análise, toma a Análise Lexical por Contexto de um Conjunto de Segmentos de Texto (ALCEST), criado por Reinert (1979). O software tem por função desenvolver a análise lexical de conteúdo, classificando os enunciados a partir de uma "distância lexical". O programa considera as "palavras plenas", portadoras de sentidos, como os substantivos, verbos, adjetivos e outras; as demais serão eliminadas. Os autores apontam duas condições para a obtenção de bons resultados no uso do software: o corpus com coerência temática e o documento volumoso o suficiente para permitir que o elemento estatístico seja considerado. Eles chamam a atenção para o fato de que os softwares não garantem por si a interpretação dos dados. Caberá ao pesquisador a recuperação, sob forma de textos, das visões parciais $\square$ e locais dos enunciados sobre o objeto de estudo, somando-se a isso a aproximação do contexto de produção dos dados. Para os autores, o processo de interpretação consistirá na correspondência de dois universos: do observável e dos modelos.

Finalizando a segunda parte do livro, Margot Madeira, no sexto artigo, explora os conceitos de objetivação e ancoragem para apreender as representações sociais de escola de diferentes sujeitos: professores e pais de alunos dos primeiros anos do ensino fundamental, jovens e adultos em processo de alfabetização e analfabetos adultos em Natal RN. Segundo a autora, esses processos garantem aos sujeitos formas de se apropriarem dos conhecimentos de seu contexto social, bem como de se reconhecerem e serem reconhecidos nas relações com os outros e com os objetos. Os resultados apontaram que os professores apresentam a escola num discurso generalizante, sem considerar suas finalidades e sua atuação.
"Fracasso escolar e suas relações com o trabalho infantil: representações de alunos repetentes, trabalhadores e não-trabalhadores e de seus professores" é o sétimo artigo do livro. Foi escrito por Alda Judith Alves-Mazzotti e integra a terceira parte da referida obra. A autora apresenta resultados de pesquisa que focalizou o fracasso escolar e suas relações com o trabalho infantil nas representações sociais de alunos repetentes e de seus professores. Dessa forma, esse trabalho adota a perspectiva estrutural das representações sociais como referencial teórico. O estudo desenvolvido teve uma amostra de 60 alunos repetentes ( 30 trabalhadores e 30 não trabalhadores) e 30 professores do ensino fundamental de uma escola pública do Rio de Janeiro. Os resultados apontaram que, para os professores, a reprovação dos alunos está associada a eles próprios, suas famílias, sistema escolar, governo e sociedade. Os professores indicam que os alunos trabalhadores são os mais comprometidos com os estudos. Para eles, a evasão está mais relacionada ao trabalho infanto-juvenil do que à repetição. Os docentes consideram que o fracasso escolar está atrelado a pobreza, uma vez que desagrega a família e priva a criança de alimento.

No oitavo artigo, "A escola como instituição pensante", Clarilza Prado de Souza tenta compreender a escola como instituição pensante a partir da articulação entre as visões construídas por professores, de passado, futuro e boa escola. Segundo a autora, a memória do passado da escola influencia a escola do presente. Seus resultados revelam duas categorias: falta de infraestrutura, espaço físico e formação como característica definidora da escola e tipo de relações sociais que a escola mantém em seu cotidiano. Contudo, os itens que constituem uma identidade da escola recebem uma qualificação negativa: quebrados, sujos, falta. No que tange ao futuro, trata-se de um futuro próximo, pois a escola atual não é a ideal.

Mohamed Chaib, no nono artigo - "As Representações Sociais de Si em Jovens Deficientes Visuais" -, apresenta os resultados da sua pesquisa para apreender as representações sociais que jovens deficientes visuais têm de si, contrapondo-se a outros estudos que abordam as representações dos não deficientes. Toma as representações sociais como caminho teórico-metodológico por ser uma teoria do conhecimento social. Realizou entrevistas aprofundadas com 14 deficientes visuais, sendo sete do sexo masculino e sete do sexo feminino. Os dados foram analisados a partir do paradigma interpretativo com a combinação da perspectiva teórica das representações sociais, a abordagem interpretativa da fenomenologia e os procedimentos e técnicas da estruturação de dados da Grounded Theory. Seus resultados mostram que os elementos que compõem a imagem dos sujeitos com deficiência estão 
ligados às experiências coletivas partilhadas por esses sujeitos.

No décimo artigo, "Um estudo de representações sociais de professores do ensino médio quanto à AIDS, às drogas, à violência e à prevenção: o trabalho com grupos focais", Vera Maria Nigro de Souza Placco apresenta resultados preliminares de uma pesquisa que tomou como foco as representações sociais de professores do ensino médio quanto à AIDS, às drogas, à violência e à prevenção. Utilizou-se do grupo focal, entrevistas e questionários. Teve como sujeitos professores do ensino médio de uma escola pública do estado de São Paulo.

Os resultados preliminares do estudo são apresentados em quatro categorias: a categoria prevenção, mostrando o que os professores pensam e sentem em relação ao seu papel e ao papel da família no trabalho de prevenção e em relação ao comportamento do aluno; a categoria ações de prevenção em parceria diz respeito a ações baseadas nos conhecimentos prévios dos professores e ações realizadas de forma intuitiva pelo professor; na categoria drogas emergem sentimentos revelados pelos professores e o conhecimento sobre drogas e seu uso, a representação que o professor tem da família, dos usuários de drogas; no que tange à categoria AIDS, os professores vão buscar suas representações em dois momentos, o passado e o presente: essa doença antes era vista como grave, hoje há uma diminuição desse temor e sua naturalização em relação ao doente. No passado, esse doente era estigmatizado; no presente há uma proximidade com a doença.

De modo geral, a obra "Experiência e Representação Social: Questões Teóricas e Metodológicas" traz à baila a necessidade de compreender os aspectos epistemológicos da Teoria das Representações Sociais e seus instrumentos metodológicos. Ela desperta no pesquisador um olhar mais cauteloso na definição estrutural do objeto e nas possibilidades de analisá-lo. Em cada investigação concluída temos a compreensão de que outros estudos podem ser investigados e ampliados. As Jornadas Internacionais também colaboram para tornar relevante o teor da TRS, tornando seu caráter inclusivo, junto aos pesquisadores das Ciências Humanas, Sociais e da Saúde. 